\title{
EXTENSÃO UNIVERSITÁRIA PARA O DESENVOLVIMENTO TERRITORIAL: CONTRIBUIÇÕES A PARTIR DE UMA ANÁLISE DAS CONCEPÇÕES E PRÁTICAS DE DOCENTES DA UFPEL
}

\author{
University extension for the territorial development: contributions from an analysis of the \\ conception and practices of professors UFPel
}

\begin{abstract}
RESUMO
Os objetivos deste trabalho foram mapear e descrever experiências de extensão universitária crítica vinculadas ao desenvolvimento territorial e rural-sustentável de professores da UFPel. Para tanto, foram analisados os 582 projetos de extensão cadastrados no sistema da UFPel referentes ao ano de 2015 e dos 60 destinados ao meio rural encontrados foram selecionados 14 professores/coordenadores para entrevista (um deles foi teste e outros dois não tinham disponibilidade para participação) em 2016. Com base em análise descritivo-interpretativa de 11 entrevistas foi possível identificar a necessidade de promover metodologias dialógicas-participativas de ensino e pesquisa, pois elas são o ponto de partida para a promoção do desenvolvimento sustentável por meio da valorização da identidade cultural e dos recursos naturais dos territórios rurais e reafirmando e respeitando o papel específico da universidade com a formação do ensino superior estudantil.
\end{abstract}

Darlan Pez Wociechoski

Universidade de São Paulo

darlanpez@gmail.com

Nádia Velleda Caldas

Universidade Federal de Pelotas

velleda.nadia@gmail.com

Marcio Silva Rodrigues

Universidade Federal de Pelotas

marciosilvarodrigues@gmail.com

Recebido em: 03/05/2017. Aprovado em: 03/05/2019.

Avaliado pelo sistema double blind review

Avaliador científico: Rafael Eduardo Chiodi

\begin{abstract}
The aim of this work was to map and to describe experiences of critic university extension linked to the territorial and rural-sustainable development of UFPel professors. Then, was analyzed the 582 extension projects registered in the system of the UFPel referring to the year 2015 and of the 60 directed to the rural environment found were selected 14 professors/coordinators for interview (one of them was test and other two were not available for participation) in 2016. Based on descriptive-interpretative analyze of 11 interviews it was possible to identify the need to promote dialogic-participatory teaching and research methodologies, because they are the starting point for the promotion of sustainable development through of the appreciation the cultural identity and the natural resources of the rural territories and by reaffirming and respecting the specific role of the university with student higher-education.
\end{abstract}

Palavras-chave: Educação Superior. Desenvolvimento Rural Sustentável. Ensino.

Keywords: Higher Education. Rural Sustainable Development. Education.

\section{INTRODUÇÃO}

Os conhecimentos científicos e humanísticos produzidos e propagados pelas universidades podem ser considerados fundamentais para o desenvolvimento das sociedades ocidentais na atualidade; eles beneficiam tanto o setor produtivo, em plena sociedade da informação, quanto o comportamento e as formas de organização das pessoas em geral. No Brasil, a universidade é caracterizada pela oferta indissociável das atividades de ensino, pesquisa e extensão ${ }^{1}$. Para esta última é comumente atribuído o papel da articulação da universidade com a realidade

\footnotetext{
1Promulgada em 1988 a constituição brasileira prevê, em seu Capítulo 3 (Educação, Cultura e Desporto), Art. 207, que "as universidades gozam de autonomia didático-científica, administrativa e de gestão financeira e patrimonial, e obedecerão ao princípio de indissociabilidade entre ensino, pesquisa e extensão". Esse princípio foi reafirmado de forma inequívoca no Capítulo 4 (Educação Superior) da Lei de Diretrizes e Bases da Educação Nacional (Lei nº 9.394 1996), Art. 43, inciso VII, onde consta: "promover a extensão, aberta à participação da população, visando à difusão das conquistas e benefícios resultantes da criação cultural e da pesquisa científica e tecnológica geradas na instituição". O objetivo desta incorporação é o de aproximar, dinamicamente, a Universidade com o restante da sociedade e asseverar seu comprometimento social.
} 
social das suas imediações e, portanto, o ponto que pode externar com maior clareza as suas relações com o desenvolvimento socioeconômico nos mais diversos tempos e espaços. Aceitar esse juízo obrigar-nos-á a reconhecer também que existem diferentes concepções de universidade e de desenvolvimento correlacionadas ao longo da história.

Em retrospectiva, desde o final dos anos 1980 assiste-se ao surgimento de novas orientações ao desenvolvimento, inclusive para os espaços genericamente referidos como "rurais". Tais concepções buscam superar as limitações das abordagens estritamente econômicas de desenvolvimento, as quais, dentre outros aspectos, objetivam a modernização da sua agricultura, o direcionamento dos recursos econômicos e de pessoal para o setor urbano-industrial. É nesse contexto de contraposição que surge a ideia de desenvolvimento territorial ou do que se conhece como abordagem territorial do desenvolvimento (VEIGA, 2002; FAVARETO, 2010).

Esse novo olhar está presente e pode ser constatada no discurso governamental e nos documentos oficiais que sustentaram a criação da Secretaria de Desenvolvimento Territorial, ligada ao antigo Ministério do Desenvolvimento Agrário, dos “Territórios da Cidadania", dos "Consórcios de Desenvolvimento Local e Segurança Alimentar” (CONSADs). Além disso, tal perspectiva vem sendo promovida e, em certa medida, incorporada à linguagem dos projetos de extensão levados a cabo por professores das universidades públicas por incentivo governamental ${ }^{2}$ ou pela iniciativa privada ${ }^{3}$, incluído dentro do que se conhece como "extensão universitária”, que, de um modo geral, melhor espelharia o compromisso das instituições federais de ensino superior em assumir sua vocação com a transformação social em suas áreas de influência.

Porém, a universidade pública carrega detrás de si um histórico de contradições que, em determinados pontos, se entrelaçam aos equívocos aludidos anteriormente

${ }^{2} \mathrm{O}$ Ministério do Desenvolvimento Agrário e o Conselho Nacional de Desenvolvimento Científico e Tecnológico (CNPq) criaramos Núcleos de Extensão em Desenvolvimento Territorial (NEDETs), bem como, o Fórum de Pró-Reitores de Extensão das Instituições de Educação Superior Públicas Brasileiras (FORPROEX, 2014) acolheu a discussão do tema "Extensão em Territórios". Além disso, o "Programa de Extensão Universitária (ProExt) [do governo federal] tem o objetivo de apoiar as instituições públicas de ensino superior no desenvolvimento de programas ou projetos de extensão que contribuam para a implementação de políticas públicas" (BRASIL, 2016).

${ }^{3}$ Vide, por exemplo, o trabalho de Mauerberg Junior et al (2014) sobre o papel deO Prêmio Gestão Pública e Cidadania (GPC) concedido pela Fundação Getúlio Vargas ao incentivo às práticas inovadoras de gestão promovido pelas universidades através da extensão. na esfera do desenvolvimento. Na execução dos projetos de extensão predominou, invariavelmente, uma visão autocrática e descolada da realidade, somada à intermitência e/ou descontinuidade de suas ações, a falta de conexão de sua prática com a atuação de outros órgãos e a quase total ausência de mecanismos de avaliação e monitoramento. Esse quadro parece bastante identificado com a trajetória da Universidade Federal de Pelotas, em seus quase 50 anos de existência.

Reconhecer a intersecção da extensão universitária e do desenvolvimento rural e/ou territorial é o pressuposto para delimitar um problema complexo, o qual consideramos relevante diante das implicações que acarreta para o cumprimento da função social da universidade. Dessa maneira, pretendemos ao mesmo tempo cumprir um papel teórico e propositivo de aproximar concepções de extensão e de desenvolvimento voltadas para o meio rural, como também, descrever exemplos concretos da materialização de casos de extensão universitária comprometidos com uma educação crítica que fortaleça o desenvolvimento dos territórios rurais.

Nesse sentido, o objetivo deste trabalho foi mapear e descrever concepções e práticas de extensão universitária que estejam interligadas ao que preconiza a abordagem territorial do desenvolvimento, ou àquelas imediatamente intersecionadas com ela, como o desenvolvimento rural sustentável. Para conseguirmos cumprir nosso alvo o trabalho foi estruturado da seguinte forma: após esta introdução, apresentamos o referencial teórico que busca aproximar as concepções de extensão universitária e de desenvolvimento dos espaços rurais; na sequência, descrevemos os procedimentos metodológicos adotados; depois disso, passamos à análise e discussão dos dados coletados, sobretudo na tentativa de compreender com eles colaboram para o detalhamento e elucidação da problematização; por fim, discutimos e elencamos uma proposição de intervenção para qualificação da extensão universitária e, consequentemente, para efetivação do seu compromisso social a partir dos dados da UFPel com o desenvolvimento territorial.

\subsection{Conexões entre concepções de extensão e de desenvolvimento}

O emprego formal da extensão universitária para o desenvolvimento territorial é um tema novo, devido ao recente surgimento desta abordagem no plano acadêmico e político-institucional nas últimas 
décadas no Brasil. No entanto, a utilização da extensão universitária para o desenvolvimento dos espaços rurais é antiga e remonta, na história brasileira, com o encontro de diferentes concepções de extensão e de desenvolvimento.

Os estudos de Silva e Speller (1999) e Silva (2001) apresentam uma forma bastante ilustrativa para compreender e sintetizar as concepções da extensão universitária e as funções da universidade a ela inerentes que perpassaram na recente história da educação superior brasileira. Para Silva (2001), conforme o Quadro 1, três visões são perceptíveis de universidade-extensão, as quais se traduzem nos seguintes termos: tradicional (ou funcionalista), processual e crítica.

Compreendido nosso alinhamento teórico com as delimitações expostas por Silva (2001), julgamos necessário resgatar brevemente os alinhamentos destas concepções com os modelos de desenvolvimento direcionados ao meio rural. Em especial, da intersecção da concepção tradicional com a visão economicista do desenvolvimento agrícola, predominantes no pósguerra. Também, procuramos rediscutir os contrapontos realizados a este alinhamento, tanto sob o ponto de vista da extensão, quanto do desenvolvimento. Por fim, culminamos em uma aproximação propositiva da concepção crítica de extensão universitária para o desenvolvimento territorial.

Inicialmente, a extensão voltada para o meio rural no Brasil tem seus primeiros registros nas atividades promovidas pelas Escolas Superiores de Agronomia de Lavras e Viçosa, em Minas Gerais, no início do século passado. Tais atividades eram inspiradas no modelo extensionista norte-americano praticado nos Land Grant Colleges e caracterizavam-se pela prestação de serviços a agricultores, com vistas à conservação dos solos, a mecanização agrícola e, consequentemente, com objetivo finalístico, do aumento da produtividade agropecuária (RIBEIRO, 2006; SOUSA, 2010).

Visivelmente, nesse período, o alvo da extensão voltada para o meio rural era hegemonicamente a difusão de tecnologias para modernização do setor agropecuário. Este período foi posterior ao final da segunda Guerra Mundial, no qual o Brasil teve suas fronteiras agrícolas expandidas, com especial ênfase no centro-oeste. Dessa forma, iniciava-se neste período o incentivo à produção em larga escala de commodities, liberação da mão de obra do campo para o setor urbano-industrial e a geração de divisas para financiamento deste último setor. Além disso, presenciou o fenômeno conhecido

\section{QUADRO 1 - Concepções de Extensão}

\begin{tabular}{|c|c|c|}
\hline Concepção tradicional & Concepção processual & Concepção crítica \\
\hline $\begin{array}{l}\text { A Universidade é vista como } \\
\text { um complemento do Estado, } \\
\text { desempenhando o papel de mera } \\
\text { executora das políticas educacionais. } \\
\text { A Extensão é entendida como uma } \\
\text { função específica, autônoma, sendo } \\
\text { a desarticulação com o Ensino e a } \\
\text { Pesquisa praticada e considerada } \\
\text { natural. A Extensão baseia-se no } \\
\text { atendimento das carências imediatas } \\
\text { da população, em uma perspectiva } \\
\text { apolítica e assistencialista. Há um } \\
\text { discurso inflamado que a coloca } \\
\text { na condição de representar a saída } \\
\text { para a Universidade, no sentido } \\
\text { de desenvolver o vínculo com a } \\
\text { sociedade, mas contraditoriamente, } \\
\text { na prática, ela acaba reduzindo-se } \\
\text { a ações esporádicas, eventuais e } \\
\text { secundárias. }\end{array}$ & $\begin{array}{l}\text { Esta concepção aparece como uma reação } \\
\text { à anterior pelo caráter de politização } \\
\text { imprimido às ações e de combate ao } \\
\text { assistencialismo. A Extensão não mais } \\
\text { representa a terceira função (desprestigiada), } \\
\text { mas a articuladora entre a Universidade e as } \\
\text { necessidades sociais, passando, então, a ter } \\
\text { uma tarefa: a de promover o compromisso } \\
\text { social da instituição. Sendo assim, adquire } \\
\text { um espaço próprio na sua estrutura sob a } \\
\text { forma de pró-reitoria, coordenação, etc., } \\
\text { justificando-se tal aparato por garantir que } \\
\text { as demandas da sociedade sejam absorvidas. } \\
\text { É a Extensão representando a "consciência } \\
\text { social da universidade". Para superar a visão } \\
\text { fragmentária que eventualmente se formasse, } \\
\text { propõe-se a articulação da Extensão com o } \\
\text { Ensino e a Pesquisa, o que fica consagrado } \\
\text { em lei. Atualmente, a concepção aqui } \\
\text { exposta é a oficial na maioria das instituições } \\
\text { universitárias. }\end{array}$ & $\begin{array}{l}\text { Esta tendência surge como uma nova } \\
\text { leitura de Extensão, que se diferencia } \\
\text { das anteriores. Nela, a Extensão está } \\
\text { intrinsicamente ligada ao Ensino } \\
\text { e à Pesquisa, é sua essência, sua } \\
\text { característica básica, apenas efetivando- } \\
\text { se por meio dessas funções. Portanto, } \\
\text { passa a ser entendida como matéria de } \\
\text { currículo. Não se justifica, assim, sua } \\
\text { institucionalização, pois não se concebe } \\
\text { que esta tenha vida própria, autonomia. } \\
\text { Daí dizer-se que "a extensão é duas, não } \\
\text { é três. Do raciocínio nós eliminamos a } \\
\text { extensão. Ela se transforma em ensino } \\
\text { e pesquisa (AZAMBUJA, 1997, p, } \\
\text { 43)". Transforma-se em um conceito } \\
\text { ocioso, porém exige que o Ensino } \\
\text { e a Pesquisa sejam comprometidos } \\
\text { com a realidade, que o conhecimento } \\
\text { produzido e transmitido seja inserido e } \\
\text { contextualizado nesta realidade. }\end{array}$ \\
\hline
\end{tabular}

Fonte: Adaptado de Silva (2001, p. 97 - 98) 
como "Revolução Verde" que apregoava o uso intensivo de máquinas, fertilizantes, sementes melhoradas geneticamente etc. O meio rural, nesta ótica, era visto unicamente como um setor produtivo e como atrasado - principalmente, aquelas agriculturas em que não aderiram aos pacotes tecnológicos dos extensionistas -, demodo que, em oposição, o setor urbano-industrial era considerado moderno e como sinônimo de desenvolvimento. Para dar conta da promoção deste modelo de desenvolvimento, agências de pesquisa e extensão foram criadas, bem como as universidades também tiveram um papel estratégico.

A primeira grande expansão e reorganização do sistema de educação superior brasileiro - que incorporou com pujança a extensão universitária pelo poder central do governo federal - deu-se apenas no período da ditadura militar (SOUSA, 2010) e coincidia com o auge da modernização agrícola. Neste período foram promovidos programas como Rondon, CRUTAC e Campi Avançados. Ponderamos que, a visão predominante de extensão universitária era a tradicional - realizada de maneira assistencialista e apolítica. Quando analisada em conjunto, a extensão voltada para o meio rural praticada pelas universidades e agências especializadas ${ }^{4}$, consideramos que, existiram os mesmos traços destas ações voltadas para modernização da agricultura e desenvolvimento agrícola nas duas organizações.

Dessa forma, restava aos agentes das duas organizações o papel de "depositar" os conhecimentos e tecnologias naqueles que não conheciam, para que os mesmos superassem estágios inferiores de desenvolvimento agrícola e migrassem para moderna agricultura. Ocorria, no entretanto, o problema da invasão cultural através de uma educação "bancária" realizada por estes agentes - como descrito por Paulo Freire na copiosa obra "Extensão ou comunicação?" (FREIRE, 2006).

$\mathrm{O}$ educador brasileiro direcionava sua crítica ao trabalho realizado por agrônomos de agências de extensão agrícola. É importante destacar este aspecto na obra de Freire, pois ao que nos parece, as críticas foram incorporadas pela extensão universitária com a manutenção do ethos das agências, que não detinham pesquisa e formação profissional inicial. É nestes termos que procuramos recordar alguns contrapontos à concepção tradicional da extensão e nas questões

${ }^{4}$ Tendo em vista que nesta época o Brasil não tinha um desenvolvido sistema de educação superior como nos Estados Unidos da América, a extensão passou a ser ofertada por organizações não universitárias, destacadamente pelas Associações de Crédito e Assistência Rural (ACAR). implicadas às instituições de educação superior. Além daqueles realizados por Freire (2006) que incidem na concepção pedagógica da ação extensionista, Botomé (2001) traz importantes contribuições para compreendê-la na esfera universitária. Isso porque, o mesmo detalha a trajetória de extensão universitária denunciando um papel compensatório da mesma.

Em uma primeira etapa, a extensão aparece e se autodefine como "redentora" da pesquisa científica e do ensino superior. Pouco tempo depois, a extensão é reconhecida como uma "terceira" atividade das universidades: um terceiro "pé" que apoia a inserção social da universidade. Logo a seguir, de redentora e de terceiro “pé", a extensão universitária passa a ser "o caminho da redenção", sendo a "via de mão dupla": levando a universidade à sociedade e esta à universidade. Mesmo mantido o discurso oficial nessas metáforas e concepções, o processo de realização das atividades de extensão universitária prosseguiria. Os anos seguintes iriam encontrar a extensão universitária começando a ter o papel de "anúncio e propaganda" da universidade. Ela passava a ser uma "face" (fechada?) que administradores e governos queriam mostrar como "sendo a universidade". Com isso, a extensão passa a ser utilizada como aparência de compromisso social, camuflando mais do que comprometendo o trabalho da universidade com a sociedade. (BOTOMÉ, 2001, p. 162, destaques no original)

Em suma, quando a extensão universitária é incorporada pelo Estado brasileiro, a mesma foi concebida como apolítica, assistencialista, desarticulada da pesquisa e do ensino e caracterizada pela realização de atividades esporádicas, por meio de um método pedagógico diretivo. Entendemos que, com a incorporação das críticas feitas por Freire à extensão universitária tradicional, a mesma passou a ter uma concepção processual, pois ao combater o assistencialismo, ela reforça seu compromisso social e procura articular-se com o ensino e a pesquisa. No entanto, utilizando das palavras de Botomé (2001), tal concepção acaba mais se distanciando que se comprometendo, por imprimir na extensão uma compensação de um ensino alienante e uma pesquisa alienada. Ou seja, a extensão se fosse realmente da universidade e estivesse embebida na pedagogia crítica, estaria operando através do ensino e da pesquisa, incorporada aos currículos - como advoga Silva (2001) sobre a concepção crítica de extensão, à qual nos alinhamos.

Dessa forma, uma extensão crítica trabalharia fundamentalmente com o caráter comunicacional e das trocas de saberes através da pesquisa - com utilização de metodologias participativas, destacando-se aqui, recentemente, a 
pesquisa-ação e a ecologia de saberes (SANTOS, 2011) - e através do ensino no tocante do aprendizado dos alunos com o meio não acadêmico, fortalecendo sua formação profissional. Logicamente, levando em conta o caráter comunicacional da extensão, aqueles que não fizessem parte do meio acadêmico também se beneficiariam com o acesso aos saberes sistematizados das ciências e humanidades. Da mesma forma, por exemplo, a geração de tecnologias e inovações cocriadas com a comunidade, através de pesquisas participativas poderia beneficiá-la diretamente.

Esses traços da extensão crítica são fundamentais para abordagem territorial do desenvolvimento, que surgiu juntamente com outros enfoques contemporâneos do desenvolvimento, em especial aquele voltado para o desenvolvimento rural sustentável, para contrapor-se ao modelo economicista. Isso porque, esses novos enfoques surgiram nos anos de 1980, uma vez que,a abordagem econômica clássica do desenvolvimento começou a enfrentar alguns problemas e limites atrelados ao próprio modelo agrícola produtivista (SCHNEIDER, 2004; WANDERLEY, 2000), que estaria em fase de superação (SCHNEIDER, 2004). A "crise" da modernização da agricultura, iniciada nos anos 1980, apresenta três dimensões (econômica, social e ambiental). A dimensão econômica da crise decorreu da superprodução agropecuária sem a devida demanda; a dimensão do colapso no âmbito social decorre da desocupação de mão de obra da agricultura, causada pela implementação de tecnologias; já a dimensão ambiental é resultado do uso indiscriminado de agroquímicos e da degradação dos recursos naturais (LAMARCHE, 1993). Gerou-se, através desta conjuntura, um amplo e intenso debate que visa repensar as concepções dominantes de desenvolvimento. A ênfase está no reconhecimento dos equívocos, mas também na busca pela "erradicação da pobreza rural, a questão do protagonismo dos atores sociais e sua participação política, o território como unidade de referência e a preocupação central com a sustentabilidade ambiental" (SCHNEIDER, 2004, p. 7).

Em meio a essa busca pela valorização dos aspectos ambientais do espaço rural, entra em curso um repensar "do rural" e da ruralidade, de modo a incorporar os imperativos da sustentabilidade e, destacadamente, a valorização dos atores sociais desse espaço e de sua cultura. Wanderley (2000) assevera o surgimento desta nova ruralidade, apontando "o rural" como espaço dinâmico e permeado de conflitos, em especial sobre aquelas que dizem respeito ao uso agrícola e a preservação ambiental. Pois, "o 'rural' não se constitui como uma essência, imutável, que poderia ser encontrada em cada sociedade. Ao contrário, esta é uma categoria histórica que se transforma" (WANDERLEY, 2000, p. 88). Nesse contexto, vale frisar que o meio rural não é simples, dado que os critérios de classificação são bastante variados em diferentes países (WANDERLEY, 2000).

Assim, passa-se de uma visão baseada num setor da economia responsável pela produção de alimentos, fibras e demais matérias primas, para um rural agora compreendido como um espaço plural, de produção de alimentos, de moradia primária ou secundária, de conservação dos recursos naturais e de turismo. Essas afirmações encontram respaldo através dos resultados do Projeto Rurbano coordenado por Graziano da Silva (2001, p. 39), ao demonstrar que há "um número crescente de pessoas que residem em áreas rurais [e que] estão hoje ocupadas em atividades não-agrícolas" no Brasil.

Sacco dos Anjos (2003) descreve a transição do enfoque setorial para o espacial no âmbito das políticas de desenvolvimento rural e na própria Política Agrária Comum da Comunidade Econômica Europeia (atual União Europeia). Além disso, o autor descreve o antecedente da Política Agrária Comum que anteriormente era voltada à visão setorial produtivista da agricultura e, posteriormente, é alterada devido aos resultados de diversos estudos, dentre eles, o trabalho "O Futuro do Mundo Rural". Tal estudo constatou que o meio rural "não pode estar simplesmente reduzido ao cumprimento de funções produtivas, devendo jogar um papel decisivo no tema do equilíbrio ecológico e do suporte às atividades de ócio e recreação" (SACCO DOS ANJOS, 2003, p. 72). Ainda conforme o autor, nessa nova filosofia de intervenção no meio rural, quando se trata da esfera produtiva, se propõe a estimular a "incorporação de valor aos produtos no seio do próprio estabelecimento ou da exploração de novas linhas de atuação com ênfase nos chamados 'nichos de mercado' (locais, denominações de origem ou produtos especiais)" (SACCO DOS ANJOS, 2003, p. 73, destacado no original).

Portanto, percebemos que a concepção de extensão crítica é imprescindível para promoção do desenvolvimento territorial, pois, esta primeira, enaltece o papel políticosocial e cultural do conhecimento através do ensino e da pesquisa, valorizando os saberes populares como fonte de aprendizagem, e, por esta última, envolver obrigatoriamente a mobilização dos atores sociais do território para construção do desenvolvimento e, também, por deter, principalmente, como ponto de partida a identidade cultural do território na formulação de estratégias de desenvolvimento. Diferentemente do modelo de desenvolvimento de viés econômico clássico que atribuía às comunidades 
um papel secundário e/ou passivo na tomada de decisões para o desenvolvimento, porque se tratavam de políticas verticais, realizadas "de cima para baixo".

\section{METODOLOGIA}

Com o intuito de mapearmos e descrevermos docentes com concepções e práticas críticas de extensão universitária que estão voltadas para as formas contemporâneas de desenvolvimento do meio rural, neste caso, desenvolvimento territorial e rural sustentável, fizemos em um primeiro momento, uma delimitação dos sujeitos da pesquisa. Os esforços foram situados naqueles docentes com atividades formalmente cadastradas em projetos e programas de extensão universitária no anode 2015 no Sistema de Extensão (SIEx) da Pró-Reitoria de Extensão e Cultura da Universidade Federal de Pelotas ${ }^{5}$. Dessa forma, ocorreu a coleta de dados secundários, através de documentos, que foram submetidos à análise documental. Basicamente visou-sea delimitação de campo com base na natureza dos projetos;nesse sentido, os dados foram classificados em dois temas principais: não-rural e rural. Ao final, dos 582 programas e projetos cadastrados até março de 2015, foram encontrados através da análise 60 projetos de extensão direcionados ao meio rural, sob a coordenação de 51 professores.

Destes professores, em um segundo momento da pesquisa, foram selecionados e convidados, intencionalmente, 14 coordenadores de projetos de extensão que promovessem neles atividades implicadas ao desenvolvimento territorial e a agricultura familiar ${ }^{6}$, sendo um deles destinado para a realização de uma entrevista-teste. Apenas dois professores não tiveram disponibilidade de tempo para participar da entrevista. Logo, foram realizadas 12 entrevistas com base em questões semiestruturadas e tinham como objetivo descrever o cotidiano do trabalho universitário desempenhado pelos docentes, além da averiguação das concepções de extensão universitária e de desenvolvimento dos mesmos. Vale destacar que elas foram realizadas no ambiente de trabalho dos docentes e todas foram gravadas e transcritas, mediante permissão dos coordenadores. Os dados obtidos a partir das entrevistas foram submetidos à análisedescritivo-interpretativa. De modo que, a categorização dos dados na análise deu-se a partir dos próprios resultados parciais, a qual permitiu

${ }^{5}$ SIEx: https://wp.ufpel.edu.br/prec/siex/

${ }^{6}$ Tal seleção decorreu, igualmente, da facilidade de acesso à maioria dos sujeitos, pois o pesquisador era egresso da Faculdade de Agronomia Eliseu Maciel/UFPel identificar dois professores que contribuem de maneira mais enfática, através de suas concepções e práticas, para apresentarmos algumas proposições para a extensão universitária voltada ao desenvolvimento sustentável dos territórios rurais, a partir deste estudo.

É importante ressaltar, por fim, que estes professores foram os quais avaliamos - a partir dos resultados parciais - como pertencentes de uma conjunção de concepção de extensão universitária crítica e de concepções de desenvolvimento rural sustentável ou territorial, enquanto que os demais estavam implicados em outras conjunções de concepções extensionistas e de desenvolvimento para o meio rural.

\subsection{Concepções e práticas de extensão crítica e de desenvolvimento territorial e rural sustentável na UFPel.}

Os dois professores que trazemos para ilustrar as práticas de extensão crítica estão lotados na Faculdade de Agronomia Eliseu Maciel (FAEM/UFPel). Eles incorporam o viés crítico educativo em sua concepção e prática extensionista. Ao tratar-se da ótica de trabalho e do enfoque dado para o desenvolvimento, o primeiro direciona-se ao enfoque "rural sustentável" (Professor 1), porque utiliza do agroecossistema e da comunidade para suporte de suas ações direcionadas, inicialmente, para produção agroecológica, enquanto que, o segundo (Professor 2) procura incorporar os imperativos da abordagem territorial, porquanto, trabalha com uma visão local/regional da vitivinicultura como propulsionadora de multifuncionalidades na propriedade rural.

Ao que se refere ao fazer extensionista do Professor 1, este trabalha com metodologias de pesquisa participativas e percebe a pesquisa, o ensino e a extensão entremeados no processo de construção do conhecimento com a comunidade. O mesmo professor nota:

[...] na verdade essas coisas todas se misturam. A pesquisa que é feita nas propriedades, o retorno do que vem pra aula, da aula volta pro campo, então, na verdade isso é uma... [...] Que hoje na realidade você vincula a sua pesquisa nesse contexto, não tem como ser diferente [...] tem pesquisa, experimentos dentro das propriedades [...] Se trabalha com agricultores, com e para agricultores. Essa é a nossa filosofia. [...] Fundamentalmente [com] metodologias participativas [...] essa nossa prática, a práxis nossa de estar lá com a família, conversar, busca informação, vê como funciona, vê a dinâmica de funcionamento do agroecossistema, vê como é que funciona/como é que se organiza a família/o agricultor [...]. (PROFESSOR 1) 
Quando questionado objetivamente à respeito de suas percepções sobre a extensão universitária sobressaiu diretamente a influência da extensão rural, em especial de suas assimilações das ideias de Paulo Freire. O que nos leva a conceber uma apropriação de fato das proposições de Freire por este professor deve-se à incorporação de metodologias de pesquisa participativas, que exigem um pesquisador-extensionista, diferentemente do sistema brasileiro de extensão rural que tem, em geral, em órgãos distintos as pessoas responsáveis pela pesquisa e pela extensão; como é sublinhado pelo próprio professor:

A extensão é parecida... é. A extensão universitária é muito parecida com a extensão rural, eu acho que majoritariamente o pessoal estende coisas, ao invés de ir lá, se envolver, construir coletivamente, participar, ser responsável, ser cúmplice, não chegar lá e querendo invadir culturalmente uma propriedade, mas esse é o modelo de extensão que idealizado no Brasil, pensou a extensão rural nele... perdura, é claro que se modificou bastante, mas hegemonicamente ainda é esse modelo. Você vai lá a Embrapa gera a tecnologia, transfere a tecnologia, pega o extensionista e vai lá, faz o dia de campo, faz uma propriedade demonstrativa, faz um monte de coisas, eu acho que essa é uma lógica equivocada. Nossos trabalhos com agricultores aqui ele pauta muito em as ideias de Paulo Freire, uma lógica de Edgar Morin, a gente enxerga essa relação nossa lá, uma relação de tolerância, com respeito, uma abertura, nunca deixando de lado o rigor cientifico da coisa, mas é a partir do construtivismo mesmo, você constrói a coisa, não adianta chegar lá com uma receitinha pronta, você tá fazendo igual ao que fazia... (PROFESSOR 1)

Além da realização da extensão através da pesquisa é necessário destacar a presença de estudantes neste processo, com maior destaque aos da pós-graduação, que demonstra o caráter de aprendizagem destas atividades. Nessa mesma linha trabalha o Professor 2, que descreve a necessidade de um programa que englobe pesquisa-ensino-extensão, e não separadamente como hoje ocorre.

Enfim, um programa onde tu possas ter uma descrição e demonstrar que tu trabalhas e ter basicamente na pesquisa e na extensão um instrumento de ensino. Esta é a ideia. $[\ldots .$.$] hoje a gente ainda analisa, interpreta e delibera sobre$ aprovação de projetos e de extensão, de ensino, de pesquisa e se a gente for ler muitas vezes não é nenhum, nem outro, nem outro. Então tá lá: projeto de extensão, curso de tal coisa. Eu não entendo como projeto de extensão, é um curso, se fez um curso, que que é um curso? É um curso. (PROFESSOR 2)

O Professor 2 exemplifica sua concepção de extensão universitária e permite perceber a participação dos sujeitos de fora da universidade na identificação e construção dos problemas. Bem como, da incorporação de questões propostas pelos partícipes que interferem incisivamente no próprio ato extensionista, como é o caso de uma senhora que questiona a sobreposição de ações desenvolvidas pela universidade e por outra instituição.

Comunicação. Comunicação e Interação, com quem? Com quem a gente tem atividade, enfim. Eu tenho dificuldade, talvez, de participar de um projeto ou um trabalho que eu não tenho vivência, não tenho formação, enfim. Então eu entendo extensão como vivência, como comunicação/interação. [...] É só a gente ir, ouvir, trocar ideias. E uma problemática que eu vejo no nosso trabalho é que em geral a gente quer ir pra solucionar problemas e quer dar resposta logo e normalmente não é assim. Então eu acho que a grande, a grande maturidade que tem que ter na extensão é aprender a dizer "não sei hoje, vou procurar pra ajudar" e levar a resposta que pode ser: "não sei". Fiz isso, isso e isso, conversei, testei, testamos isso, isso e isso, e não deu. [...] a gente tava numa propriedade e eu acho que eu ouvi isso pela quinta vez já, quinta ou sexta vez: "por que vocês não tem, não comprem uma Kombi venham todo mundo junto?" até eu já usei isso em minhas manifestações e de novo uma senhora lá na propriedade diz que nós éramos o sexto grupo que vinha entre universidade e Embrapa e não sei quem que ia lá pra fazer as mesmas coisas, as mesmas perguntas e que já tinham feito 20 vezes e "antes mesmo dela ter feito cirurgia da perna" também tinham ido lá e feito as mesmas perguntas e ninguém resolveu nada. O que eu quero dizer com isto? É que sim, talvez a gente não faça extensão, a gente vai lá fazer questionários e uma tentativa de conhecer o que está acontecendo e achar que a gente tá com o problema pronto e quer levar soluções. Então eu diria assim, o pressuposto básico da extensão é, bom, primeiro é: ouvir, é ouvir e conhecer [...] Conhecer aquela realidade, bom, se é um problema, qual é a origem e como é que nós podemos solucionar. (PROFESSOR 2)

Aí está um ponto que distingue os professores que pertencem a concepção crítica da processual e tradicional: a valorização dos sujeitos na concepção crítica, não, pelo contrário, a coisificação dos sujeitos; os mesmos tornando-se meros objetos de observação na concepção tradicional/funcionalista ou processual. Conhecer a realidade na concepção crítica de extensão significa envolver o restante da sociedade, sempre que possível e necessário, na identificação e resolução dos problemas. Não se trata, porém, de esperar as mudanças unicamente do restante da sociedade ou de desvalorizar os conhecimentos acadêmicos em relação aos populares, a universidade e o restante da sociedade devem, em um mesmo pé de igualdade, 
se tornar cúmplices na construção de um mundo menos desigual e mais justo.

A promoção do desenvolvimento territorial obriga o uso desta postura extensionista crítica, pois envolve uma atuação do Estado - neste caso, representado pela universidade pública - essencialmente em conjunto com os demais atores sociais, pois, reiterando a assertiva de Pecqueur (2005, p. 12), de que "o desenvolvimento territorial designa todo processo de mobilização dos atores que leve à elaboração de uma estratégia de adaptação aos limites externos, na base de uma identificação coletiva com uma cultura e um território".

Nesta perspectiva, podemos perceber que os professores 1 e 2 procuram incorporar a participação da comunidade nas decisões das estratégias, para o desenvolvimento dos locais que fazem parte. Mas, cada qual, com focos específicos de trabalho. O Professor 1 descreve seu trabalho voltado à agricultura através da agroecologia:

O foco nosso hoje fundamental é $[. .$.$] tentar construir$ uma agricultura que seja mais humanizada, mais harmônica com a natureza, não se tem uma coisa assim engessada. Ah, se o cara não fizer isso já é bandido. Não. Vamos com calma. O propósito é tentar fazer algo diferente do que está sendo feito até esse momento, por quê? Porque a gente avalia que o que está sendo feito até agora hegemonicamente não tem dado resultado adequando dentro das nossas percepções, concepções de vida, de sociedade, de mundo, de agricultura, então isso tem nos levado para um outro caminho. Isso é uma coisa que é gradativa, continua, não tem uma parada, vai adiante sempre, sendo construído. Mas a nossa lógica é essa. Como ferramenta tá se usando muito a questão da agroecologia, nem todos os projetos, mas em muitos se usa a agroecologia como ferramenta através do quê? Dos agricultores que são sujeitos do processo de construção desse conhecimento. (PROFESSOR 1)

Conforme exposto, este professor está mais direcionado ao desenvolvimento rural sustentável, pois, não há evidencias de um rompimento da visão setorial. Fica mais evidente esta posição quando questionado objetivamente se seu projeto estaria voltado para o desenvolvimento territorial, o mesmo associou o território como unidade de referência ao agroecossistema, ou a comunidade, mas não propriamente a compreensão da visão "multissetorial"ou "espacial" quea abordagem carrega (VEIGA, 2002; SACCO DOS ANJOS, 2003). Como pode ser observado nas palavras do próprio professor:

Eu acho que tá implícito. Principalmente a comunidade. Talvez assim ó, mais do que território, mais do que território, a comunidade talvez seja... é o elo, é o conjunto das propriedades que a gente trabalha às vezes a gente consegue fica dentro de uma comunidade, então tem isso, os resultados, o foco, o que resulta, os reflexos se sentem mais na comunidade do que no território. Claro, o conjunto das comunidades formam um território. Mas tem ligação certamente. [...] A gente tem até nos nossos trabalhos foco quando se relaciona com coisas que faça referência com o "Território Zona Sul" do Rio Grande do Sul, em função dos nossos convênios com o CAPA, ele se articula e tal, mas a gente está mais focado no agroecossistema e, depois, na comunidade. Que o nosso agir, o nosso atuar, o nosso operar ele é limitado em função das nossas possibilidades, nós somos poucas pessoas que trabalham diretamente com agricultores, então isso dificulta. Não tem, daqui a pouco um professor lá tem aula aqui tem aula não sei o que, trabalhar fora implica em tu ir lá em Canguçu, ir lá não sei a onde, ir lá no Remanso, $70 \mathrm{Km}$ daqui, lá no Nilo é um dia inteiro. Então, é muito concentrado o trabalho pra poucas pessoas. Por isso que o foco é no agroecossistema. Que aliás o agroecossistema é o objeto de análise dentro da perspectiva agroecológica. Saí ali na comunidade e já é uma extensão daquilo, mas o nosso foco é o agroecossistema. Claro que no fundo depois vai resultar nisso. Melhorar assim a vida da família. Certamente vai refletir na comunidade. (PROFESSOR 1)

Por outro lado, dos propósitos da abordagem territorial, o rompimento com a visão setorial e com uma nova ruralidade (WANDERLEY, 2000; SACCO DOS ANJOS, 2003), aparecem notoriamente na descrição do trabalho do Professor 2. Inicialmente o professor descreve que seu projeto estaria direcionado especificamente para produção agrícola e beneficiamento agroindustrial, mas que seria também "Uma atividade propulsionadora de multifunções na propriedade" (PROFESSOR 2). Isso porque, "se tu fores conversar com as famílias que estão investindo, praticamente o negócio se torna inviável se não tiver essa perspectiva" (PROFESSOR 2). Dentre outras atividades geradas na propriedade o professor destaca a paisagística e o turismo, bem como, corrobora com a indispensável preservação ambiental.

[...] Com certeza, paisagem e o turismo. Só que pensar assim, só se fazer parte de um grupo que recebe turista, é um pouco mais amplo. É participar de eventos que envolvam o turismo, o turismo como um tudo, não é só receber na propriedade é ir também em feiras e eventos, enfim. Praticamente todo mundo precisa fazer isso. (PROFESSOR 2)

Ao ser questionado sobre a vinculação do seu projeto com alguma concepção de desenvolvimento e sobre sua própria concepção, o Professor 2 utiliza da descrição de suas ações para responder: 
A ideia, assim, muito do que eu participo é começar muito do mínimo para o máximo. Então, sempre é um grande desafio quando uma família diz assim: poxa, gostaria de fazer isso... sempre penso: é o que nós podemos contribuir dentro das perguntas que estão fazendo para que essa família viva bem nesta propriedade, não sinta a necessidade de buscar outra... outras alternativas. Seja: se deslocar para o centro urbano, vende e etc. Então, desenvolvimento rural, eu penso que sim. Regional, nosso envolvimento nas possibilidades de IGP penso que daria um sotaque regional. O nosso trabalho como um formulador de uma política pública que venha mudar... se eu for escrever isso eu vou estar me traindo exatamente naquilo que eu dizia, escrever um texto sem ter feito. Nós não chegamos nessa amplitude. 'Ah, mas nós participamos ativamente na formulação desse regramento'. Poxa, isso é um regramento da cantina que vai afetar 350 famílias aí no Estado. Não foi aquela política pública que mudou o desenvolvimento regional/nacional do Estado, não foi isso. Acho que é mais modesto, acho que nós ficamos no desenvolvimento rural local e um pouquinho regional, mas eu não diria que a gente, com o que a gente faz, a gente seja suficientemente forte, conceitual para as grandes mudanças. (PROFESSOR 2)

O trabalho do Professor 2 traz à lume uma característica importante que diferencia a abordagem territorial do desenvolvimento das demais. Trata-se das atividades agroindustriais que trabalham em uma ótica de agregação de valor, principalmente via diferenciação dos produtos, através das características inerentes do território no qual são produzidos, com destaque as Indicações Geográficas de Procedência (IGP). Ou seja, além de poder atender aos mercados locais, também são direcionados para outros mercados. Enquanto que, por outro lado, os empreendimentos voltados para produção agropecuária e ao beneficiamento numa concepção agrícola, em tese, trabalham direcionados prioritariamente a agregação de valor pela escala de produção.

\section{CONSIDERAÇÕES FINAIS}

Ao observarmos em retrospecto os dados dos professores descritos, percebemos a convergência na esfera da extensão para utilização de pesquisas dialógico-participativas realizadas com estudantes, e, ao que se refere ao desenvolvimento, umadiferenciaçãomínimano foco específico de trabalho para o desenvolvimentode cada professor, pois um deles tem uma visão que abrange mais funcionalidades do meio rural do que o outro.

Os dois professores incorporam as proposições de Paulo Freire para o extensionismo.O primeirodeles de modo mais explícito, cita, inclusive, as ideias do educador para fundamentar suas ações. Seu trabalho parte de metodologias participativas $^{7}$ de pesquisa, com destaque a utilização de unidades experimentais nas propriedades de agricultores familiares. Enquanto o Professor 2, demonstra de modo implícito as ideias que Freire (2006) defende, pois sua ênfase recai na compreensão do papel comunicacional da extensão, na qual os sujeitos que não fazem parte da academia também participam do processo de identificação dos problemas e resolução dos mesmos. Ambospercebem uma saudável "confusão" do ensino, da pesquisa e da extensão. Ao passo que, o Professor 2, defende que seja criado pela gestão central da universidade o formato de cadastro de programas de ensino-pesquisa-extensão, diferentemente de como é realizado atualmente, em que são cadastradas em projetos de atividades separadas (projeto de ensino, projeto de pesquisa e projeto de extensão). Os dois professores também são críticos ao extensionismo em geralpraticadona universidade - trata-sedaquele desenvolvido na concepção tradicional, que "estende" coisas em uma visão educativa bancária (FREIRE, 2006), na qual as pessoas que não fazem parte da academia recebem, como os próprios professores descrevem, cursos e pacotes tecnológicos prontos e/ou são alvo de pesquisas que os reduzem a objetos de análise de questionários; desmerecendo, desta forma, a possibilidade de troca de saberes sistematizados com os populares. Enfim, a perspectiva de trabalho extensionista dos dois professores, principalmente, através da pesquisa, os interligam à concepção crítica de extensão descrita por Silva (2001), à qual ao envolver alunos acaba ocorrendo indissociavelmente ao ensino.

Quando nos detemos à discussão dos enfoques dos professores ao desenvolvimento, percebemos inicialmente que, há uma dificuldade imanente para trabalhar com a abordagem territorial e também classificar aquelas ações destinadas a este fim.Porém, a partir das práticas dos dois professores descritos, foi possível traçaruma indicação de como pode ser implementada a abordagem territorial do desenvolvimento, qual seja, através da utilização de metodologias dialógico-participativas de ensino-pesquisa.

Portanto, percebemos que a extensão universitária em sua concepção crítica mostra-se fundamental para promoção do desenvolvimento territorial pelas universidades, bem como, do desenvolvimento rural sustentável. Embora pareça pleonasmo insistirmos na concepção crítica, significa reforçarmos as especificidades da própria universidade

${ }^{7} \mathrm{O}$ desenvolvimento destas metodologias tem como contribuições no Brasil autores como Carlos Rodrigues Brandão, João Bosco Pinto e o próprio Paulo Freire. Além disso, são consideradas áreas de reconquista da legitimidade da universidade por Santos (2011) 
na extensão universitária. Ou seja, as ações dos membros da universidade não podem ser confundidas com as de uma agência extensionista, esta deve ter sempre suas atividades presentes nos currículos; em outras palavras, ela deve estar inserida dentro do processo de formação alunos de graduação e pós-graduação. Dessa forma, atividades de ensino e pesquisa serão sempre contextualizadas na realidade do territórioaos quais pertencem e, com isso, levarão em conta a identidade cultural de seus territórios.

Como proposição para qualificação da extensão universitária, afirmamos a necessidade de incentivo à formação inicial e continuada do docente universitário em diferentes metodologias de pesquisa e de ensino. Porquanto é evidente o valor pedagógico e cognitivo destas atividades construídas dentro de uma perspectiva dialógica, que legitima os conhecimentos provindos de origens diversas como ponto de início para o desenvolvimento territorial. Ademais, ressaltamos que não estamos aqui desmerecendo o potencial, o nível técnico e acadêmico, bem como a capacidade dos docentes e discentes como membros também legítimos da sociedade na proposição de ações, uma vez que, conforme dito anteriormente, acreditamos que a universidade e a sua comunidade devem estar em um mesmo nível de igualdade para identificação e resolução dos problemas que impedem o desenvolvimento territorial.

\section{AGRADECIMENTOS}

À Coordenação de Aperfeiçoamento de Pessoal de Nível Superior (CAPES) pela concessão de bolsa de estudos durante o mestrado, e aos avaliadores pelas contribuições ao trabalho. O presente trabalho é resultado da dissertação de mestrado intitulada "Concepções de extensão e desenvolvimento na Universidade Federal de Pelotas: uma análise a partir dos seus atores" que foi defendida em novembro de 2016 no Programa de Pós-Graduação em Desenvolvimento Territorial e Sistemas Agroindustriais da Universidade Federal de Pelotas."

\section{REFERÊNCIAS}

BOTOMÉ, Silvio Paulo. Extensão universitária: equívocos, exigências, prioridades e perspectivas para a universidade. In: FARIA, Dóris Santos de (Org.), Construção conceitual da Extensão Universitária na América Latina. Brasília: Universidade de Brasília, 2001. p. 159-175.

BRASIL. Constituição Federal de 1988. Disponível em: <http://www.planalto.gov.br/ccivil_03/Constituicao/ Constituicao.htm>. Acesso em: 15 jun. 2015.
BRASIL. Decreto n' ${ }^{\circ}$. 5.773, de 9 de maio de 2006. Dispõe sobre o exercício das funções de regulação, supervisão e avaliação de instituições de educação superior e cursos superiores de graduação. Brasília; 2006. Disponível em: $<$ http://portal.mec.gov.br/seed/arquivos/pdf/legislacao/ decreton57731.pdf $>$. Acesso em: 5 jun. 2015.

BRASIL. Lei n. 9.394, de 20 de dezembro de 1996. Estabelece as Diretrizes e Bases da Educação Nacional. Diário Oficial da União, Poder Legislativo, Brasília, DF, 23 dez 1996. p. 27833. Disponível em: <http://www. planalto.gov.br/ccivil_03/leis/19394.htm>. Acesso em: 5 jun. 2015.

BRASIL. Programa de Extensão Universitária, ProExt - Apresentação. Disponível em: <http:// portal.mec.gov.br/index.php?option=com content \&view $=$ article $\&$ id $=12241 \&$ ativo $=488 \&$ Itemid=487> Acesso em: 21 de out. 2016.

FAVARETO, Arilson da Silva. A abordagem territorial do desenvolvimento rural-mudança institucional ou “inovação por adição"? Estudos avançados, v. 24, n 68, p. 299-319, 2010.

FORPROEX. XXXVI Encontro Nacional do FORPROEX - Carta de Goiânia. RENEX, Minas Gerais, 2014. Disponível em: <https:/www.ufmg.br/proex/renex/index. php?option=com_content $\&$ view=article $\& i d=148$ : cartade-goiania> Acesso em: 24 de set. de 2016.

FREIRE, Paulo Reglus Neves. Extensão ou comunicação? $13^{\mathrm{a}}$ ed. São Paulo: Paz e Terra, 2006.

LAMARCHE, Hugues (Coord.). A agricultura familiar. Comparação internacional. Vol. I: uma realidade multiforme. Campinas: Unicamp, 1993.

MAUERBERG JUNIOR, Arnaldo; GUERREIRO, Julia; COSTA, Caio César Medeiros; FERREIRA, Marco Aurélio Marques. A universidade como espaço territorial de inovação: o papel da extensão universitária no incentivo às práticas inovadoras de gestão. Organizações Rurais \& Agroindustriais, v. 16, n. 2, p. 220-232, 2014.

PECQUEUR, Bernard. O desenvolvimento territorial: uma nova abordagem dos processos de desenvolvimento para as economias do Sul. Raízes, Campina Grande, UFCG, v.24, n.1/2, p.10-22, 2005. 
RIBEIRO, Maria das Graças Marcelo. Caubóis e Caipiras. Os Land-Grant Colleges e a Escola Superior de Agricultura de Viçosa. História da Educação (UFPel), v. 10, p. 105119, 2006.

SACCO DOS ANJOS, Flávio. Agricultura familiar, pluriatividade e desenvolvimento rural no Sul do Brasil. Pelotas: Egufpel, 2003.

SANTOS, Boaventura de Sousa. A universidade no século XXI: para uma reforma democrática e emancipatória da universidade. São Paulo: Cortez, 2011.

SCHNEIDER, Sérgio. A abordagem territorial do desenvolvimento rural e suas articulações externas. Sociologias, $\mathrm{n}^{\circ}$ 11, p. 88-125, 2004.

SILVA, José Graziano da. Velhos e novos mitos do rural brasileiro. Estudos avançados, v. 15, n. 43, p. 37-50, 2001.
SILVA, Maria das Graças Martins da. Extensão Universitária no sentido do ensino e da pesquisa. In: FARIA, Dóris Santos de (Org.), Construção conceitual da Extensão Universitária na América Latina. Brasília: Universidade de Brasília, 2001. p. 91-105.

; SPELLER, Paulo. Extensão universitária: qual o seu lugar no contexto da universidade?. Revista Educação Pública (UFMT). v. 8, n. 13. p. 229-24, 1999.

SOUSA, Ana Luiza Lima. A história da extensão universitária. $2^{\mathrm{a}}$ ed. Campinas: Alínea, 2010.

VEIGA, José Eli da. A face territorial do desenvolvimento. Revista Internacional de Desenvolvimento Local, v. 3, $\mathrm{n}^{\circ} 5$, p. 5-19, 2002.

WANDERLEY, Maria de Nazareth Baudel. A emergência de uma nova ruralidade nas sociedades modernas avançadas - o "rural" como espaço singular e ator coletivo. Estudos Sociedade e Agricultura, n. ${ }^{\circ}$ 15, p. 87-146, 2000. 